\title{
Using concurrent gait and cognitive assessments to identify impairments after concussion: a narrative review
}

\author{
David R Howell ${ }^{* 1,2,3,4}$, Michael W Kirkwood ${ }^{5,6}$, Aaron Provance ${ }^{4}$, Grant L Iverson ${ }^{7,8,9}$ \& \\ William P Meehan III', 2,3,10 \\ ${ }^{1}$ The Micheli Center for Sports Injury Prevention, Waltham, MA 02453, USA \\ ${ }^{2}$ Division of Sports Medicine, Department of Orthopaedics, Boston Children's Hospital, Boston, MA 02115, USA \\ ${ }^{3}$ Brain Injury Center, Boston Children's Hospital, Boston, MA 02115, USA \\ ${ }^{4}$ Sports Medicine Center, Children's Hospital Colorado \& University of Colorado School of Medicine, Aurora, CO 80045, USA \\ ${ }^{5}$ Department of Physical Medicine \& Rehabilitation, University of Colorado, Aurora, C0 80045, USA \\ ${ }^{6}$ Rehabilitation Medicine, Children's Hospital Colorado, Aurora, CO 80045, USA \\ ${ }^{7}$ Department of Physical Medicine \& Rehabilitation, Harvard Medical School, Spaulding Rehabilitation Hospital, Boston, MA \\ 02129, USA \\ ${ }^{8}$ Mass General Hospital for Children Sport Concussion Program, Boston, MA 02114, USA \\ ${ }^{9}$ Home Base, A Red Sox Foundation \& Massachusetts General Hospital Program, Boston, MA 02129, USA \\ ${ }^{10}$ Department of Pediatrics \& Orthopaedic Surgery, Harvard Medical School, Boston, MA 02115, USA \\ *Author for correspondence: Tel.: +1 720777 1502; Fax: +1 720777 7268; David.Howell@ucdenver.edu
}

Understanding how a concussion affects an individual is oftentimes difficult for clinicians due to the varying symptom profiles reported by the patient and the multifaceted and heterogeneous nature of the injury. Accordingly, the interpretation of postconcussion performance can be challenging, because many different testing paradigms have been reported as potentially useful in the literature. Among the types of tests clinicians use to understand how concussion affects an individual, both gait and neurocognitive evaluations have demonstrated utility. Our purpose is to describe how combined gait and cognitive (i.e., dual task), as well as single-task gait and computerized neurocognitive examinations can assist clinical decision-making.

First draft submitted: 10 March 2017; Accepted for publication: 21 December 2017; Published online: 19 January 2018

Keywords: attention • dual-task • locomotion • mild traumatic brain injury $\bullet$ neurocognition $\bullet$ recovery

It is well established that concussions can have adverse effects on cognition [1], dynamic balance [2,3], static balance $[1,4,5]$ and vestibular-oculomotor functioning [6-9]. People who sustain this injury report a diverse range of physical, cognitive and psychological symptoms [10-12]. Concussion is a multifaceted injury of the brain that affects individuals in a variable fashion [13]. Accordingly, it can be difficult to provide prognostic counsel to patients, or to determine the optimal time to resume school, work or athletic activities. Many different forms of testing have been proposed to contribute useful information to clinical evaluations after a concussion. These range from high expense and sophistication (e.g., advanced neuroimaging [14,15] and electroencephalography [16-18]), to moderate expense and sophistication (e.g., computerized neurocognitive tests [19-21]), to low expense and sophistication (e.g., Balance Error Scoring System [BESS] [22,23] and symptom inventories [24-26]). A proper balance of cost, time and added value often dictates the management practices within each setting, and leads to considerable variability among different practices throughout the USA [27,28].

Interpretation of postinjury performance can be challenging for many reasons. One potential reason is that questions remain pertaining to the natural history of concussion recovery [29,30]. Many of the effects of concussion, particularly concussions sustained during sports, resolve within 1-4 weeks postinjury for the majority of patients $[4,31,32]$, resulting in a risk of false-positive findings after this time. Specifically, symptom inventories are nonspecific to concussion and may be affected by factors other than concussion-related dysfunction, such as exercise [33,34]. Other clinical tests that are commonly used in conjunction with symptom inventories possess lim-

Future Medicine 
itations as well: the BESS is limited by practice, environmental and equipment effects [35-38], while computerized neurocognitive test performance may be influenced by sleep, prior history of concussion or attentional-deficit disorders [39-41]. Additionally, interpreting what constitutes 'abnormal' or 'unusual' performance can further complicate decision-making. Although comparison to baseline, or preinjury, performance remains the goal in many clinical situations [42], normative reference values on common concussion tests have been developed [43-50] and may allow clinicians to identify concussion-related deficits in the absence of baseline data [51]. As such, the purpose of this narrative review is to outline and discuss published studies that pertain to the clinical usefulness of dual-task gait in the management of sport-related concussion, as well as other tests of function, such as computerized neurocognitive tests or single-task gait examinations.

\section{Gait \& posture}

Both gait and balance evaluations are recommended as key features of a clinical concussion evaluation [52]. Although these terms are often used in conjunction, they both represent different aspects of postural control. Specifically, the term posture has been described as the orientation of the body relative to the vector of gravity, while balance describes how the body achieves stability during motion to avoid falling [53]. Therefore, gait occurs by maintaining an upright posture during bipedal locomotion. Gait is a relatively challenging task for the balance control system [53], and is a complex motor process that takes many years to develop during childhood [54]. No longer considered an automated motor output process, humans must be aware of, and appropriately control both limbs in space to appropriately produce gait [55].

Within the context of concussion management, balance assessments that rely on static control of posture are commonly used, while tests of dynamic motor abilities such as gait are not thought of as routine elements of a concussion examination $[27,28,56]$. Although no studies to this point have directly compared these two types of postural control deficits after a concussion, gait may involve a more complex set of motor actions required for successful completion and thus, a longer period of time required for recovery. Specifically, measurements like gait speed, stride length and interjoint coordination have contributed useful information when assessing deficits resulting from a concussion [57-59], while more in-depth measures of center of mass (COM) movement may allow researchers to understand fine motor control processes of the body and potentially identify subtle pathologic gait abnormalities after concussion $[3,60,61]$.

\section{Neurocognitive function}

Numerous studies have documented that concussion can cause impairment across a variety of cognitive domains including new learning and memory, processing speed, attention and executive functioning $[1,11,21,62-64]$. Deficits are observed whether a comparison is made to an athlete's pre-injury (baseline) status or a control group's performance [51]. The evaluation of cognition can be achieved through sideline day-of-injury mental status screening [65] or more thorough neuropsychological testing [66]. Accordingly, both have advantages and demonstrated value in helping to objectively identify acute injury effects.

Objective sideline cognitive screening (e.g., using the standardized assessment of concussion [5,31]), which can be administered by any trained professional and takes only a few minutes to complete, is more sensitive to concussion than informal orientation questions [5]. Lengthier neuropsychological testing is administered via traditional paperand-pencil measures or by computer. In the sports setting, such testing is often employed in a manner consistent with the 'baseline testing' model originally proposed in the 1980s $[67,68]$. The model involves athletes undergoing a test battery during a preseason baseline session and then repeated follow-up testing after a concussion until the athlete returns to the baseline performance. At this point, computerized neurocognitive tests are the most common form of objective testing used in sports medicine settings: approximately $30 \%$ of universities [27] and $40 \%$ of high schools [21] use some form of a computerized neurocognitive test.

\section{Dual tasks}

Although cognitive abilities are commonly assessed as a part of concussion management plans, concurrently pairing a cognitive and motor task such as gait together may allow for detection of deficits that are not identified through single-task gait or cognitive testing alone. Gait has been traditionally thought of as an automated motor process, but it is now understood that multiple neurophysiological influences may modulate walking behavior [55]. In healthy individuals, gait can be modulated by perceived physical or cognitive perturbations that force the division of 
attention while walking. This process of combining two forms of testing has been termed as dual task and has been used traditionally to assess health-status progression among aging populations at risk for falling [69-71]. Although researchers have observed considerable concussion-related dual-task impairments [2,72], they are not currently used in a widespread fashion during clinical examinations [57]. Although single tasks, such as evaluations of gait, quiet stance or neurocognitive function in isolation, require the focus of attention, dividing attention across multiple domains leads to the competition for resources. In the injured brain, this competition may result in the degradation in one or both of the domains when completed concurrently relative to an uninjured and otherwise healthy individual completing the same type of task [3].

Attentional deficits persist in some people after a concussion. Specifically, while the spatial orientation component of attention may be altered initially after injury [64], deficits in the executive component of attention (so called 'executive functions') may persist among both adolescents and young adults for a longer time period than has been typically measured using traditional clinical metrics $[5,63,64]$. Therefore, due to the reduction in attentional resources after a concussion, dual tasks may be well-suited to identify persistent impairments.

Although many dual-task concussion studies have focused on a gait and cognitive task performed concurrently, other methods have been used to examine the simultaneous completion of different functional abilities. For example, Tapper $e$ al. implemented a dual-task paradigm that combined an auditory discrimination task and a Corsi block task simultaneously [72]. They observed that those who reported a history of concussion had a more difficult time dividing attention between the two tasks relative to their peers with no concussion history. In addition, Resch et al. measured cognitive abilities while balance control was quantified in various static positions among healthy collegiate students, observing that postural control performance was prioritized over cognitive processing [73]. Furthermore, during the BESS test, the addition of a secondary cognitive task appears to improve reliability and clinical applicability within concussion evaluations [74].

Among the many current challenges for researchers and clinicians interested in potential treatments for concussion is the lack of an objective diagnostic technique and method to more accurately quantify physiologic recovery of the brain. If such measures were developed in a manner that was adaptable for widespread use, assessment of the efficacy of different concussion treatment pathways might be easier to determine. Dual-task function after a concussion, therefore, constitutes the combination of two aspects that may assist in outlining and evaluating the efficacy of future randomized control treatment or rehabilitation trials.

As our primary area of review pertained to the use of dual-task methodology (i.e., combined cognitive and gait tests) to evaluate individuals after a concussion, we conducted a review according to the Preferred Reporting Items for Systematic Reviews and Meta-Analyses (PRISMA) guidelines [75], using the following search engines: PubMed, Web of Science and Academic Search Premier (EBSCO host) from the time of database inception to January 2017. Specific search terms included sports, concussion, mild traumatic brain injury, gait, locomotion, dual task*, concurrent task* and simultaneous task*. Asterisks were used at the end of a search term to identify all terms beginning with that string. Reference lists from identified articles were also used as a supplemental search technique. All titles and associated abstracts were reviewed independently and publications that were not appropriate were excluded from the review.

\section{Single-task gait evaluations}

The measurement of single-task gait, or normal walking behavior, has been studied extensively from a neuromuscular and kinematic perspective [76-78]. In the context of body mechanics, humans walk in a relatively unstable fashion whereby the COM of the whole body regularly extends outside of the base of support area [76]. As such, bipedal locomotion requires complex neuromuscular control to prevent falling and to achieve and maintain stability. Despite the complexity of this process, gait patterns are highly consistent across time in uninjured young adults and adolescents [79]. After a concussion, this fine neuromuscular control ability may be impaired. As a result, those with a recent concussion often walk slower or with shorter strides than uninjured control counterparts during single-task gait [80-82]. Therefore, the interpretation of single-task gait behavior may provide some value in the context of concussion management.

After a concussion, sophisticated measurements of steady-state walking behavior have been useful in identifying movement pattern deficits. Using a pressure mat to measure spatio-temporal gait parameters, more conservative gait characteristics were observed in those with a history of concussion, indicated by shorter stride lengths and slower step velocities [83]. The authors suggested that this may be a result of persistent postconcussion postural control deficits that go undetected with other traditional forms of concussion testing or that it may be an early indicator 
of potential long-term neurological impairments resulting from multiple concussions. Future prospective cohort studies, however, are needed to adequately determine the cause of this observation, but these findings suggest that gait alterations may be more apparent in those with a history of multiple concussions.

The length of time that individuals with a concussion exhibit single-task gait deficits is not currently well defined. Prior research suggests that group differences between those with a concussion and matched controls exist from the time of injury and until approximately 2 weeks after injury $[3,84]$. This timeline coincides with the duration of cognitive test or symptom recovery time after concussion previously reported [31,32]. The benefits of examining dynamic balance control in addition to standard spatio-temporal variables during gait appear to be relevant in the identification of postconcussion deficits as well. Conservative gait patterns indicative of dynamic instability can be quantified by COM movement, or the interaction between the COM and the base of support during gait [85]. The location of where each foot is placed during gait may reflect the control of the whole body COM and the ability to dynamically control the body during movement [85]. Thus, neuromuscular deficits after a concussion may arise from motor control difficulties responsible for controlling where each foot is placed during locomotor progression.

The apparent inability to properly control the mass of the body during gait progression can result in more side-to-side movement (or sway) of the COM. Therefore, this variable has been used consistently to identify dynamic stability [60,85-87]. Using motion analysis, differences in gait between injured and control groups remain on measures of dynamic balance, even after there are no longer differences in self-reported symptom scores [3,84]. Although single-task gait abnormalities may exist after a concussion, quantification is difficult in most settings. Because balance testing is recommended as a part of the postconcussion evaluation, few collegiate athletic settings routinely use something other than the Balance Error Scoring System (BESS) or modified BESS (mBESS) $[27,56]$.

\section{Neurocognitive evaluation}

The evaluation of neuropsychological deficits after concussion has been reported throughout the literature, and has been reviewed in depth previously [88-90]. Their use in multifaceted concussion evaluations can provide helpful information regarding recovery from injury, particularly when test results are interpreted by a qualified neuropsychologist [52]. As mentioned previously, two methods are commonly used in the setting of sports concussion to evaluate cognitive functions: brief sideline screening and lengthier neuropsychological testing. Acute screening of mental status within hours of a suspected concussion may be one way to assist with concussion diagnosis $[1,31,91]$ and is widely agreed to be important for assisting with immediate management [42,92,93]. Lengthier neuropsychological testing in the baseline model was once viewed as the 'cornerstone of concussion evaluation', [66,94] primarily because of its intuitive appeal, objective nature and resultant agreement statements from a number of professional organizations $[42,92,93,95]$.

Practical advantages of baseline computerized testing are frequently promoted to justify its use including the ability to test many athletes simultaneously during the preseason, widespread availability, ease of administration and scoring, access to alternate test forms and ready creation of centralized data repositories. Computerized cognitive testing in the acute period may also be helpful for identifying athletes at risk for slower than expected recoveries [96,97] and identifying difficulties in athletes who no longer report symptoms [98]. Specifically, Broglio et al. identified that once asymptomatic after concussion, approximately $38 \%$ of athletes continued to demonstrate a deficit in at least one domain of neurocognitive function, such as verbal memory, visual memory, visual-motor speed or reaction time [98]. At the same time, concerns have been expressed that the promotion of computerized tests has outpaced their clinical evidence $[99,100]$. Despite these concerns, computerized neurocognitive tests possess clinical value in ability to recognize potential deficits beyond symptom inventories, particularly when used in the first week after a concussion [101].

Increased scrutiny of the empirical literature over the last decade has led to questions about the clinical utility of baseline testing as used popularly. Testing an athlete during the preseason requires time, effort and money. Although the collection of baseline data is ideal, recent studies suggest that neurocognitive data may be useful, even in the absence of baseline data, by comparing to normative values $[51,102,103]$. Other questions relate to whether the available tests have robust enough psychometric properties to allow for the accurate detection of change within the context of modest-to-poor test-retest reliability. Some studies have found poor test-retest reliabilities [99,100]. A recent study compared three commonly used computerized cognitive batteries (ANAM, Axon Sports/Cogstate Sport and ImPACT) and found that only about a quarter of the test indices had moderate stability coefficients $(r>0.70)$ [101]. Moreover, although the tests were found to be reasonably sensitive to concussion within the first $24 \mathrm{~h}$ 
of injury, the sensitivity was near the false-positive rate established by nonconcussed athletes by 8 days postinjury, due in large part to clinical recovery.

Baseline cognitive testing has some methodological challenges and limitations. First, there is some evidence that athletes tested in a group setting perform more poorly on computerized cognitive testing than those tested individually [104], and they also have a somewhat greater rate of invalid scores [104] - but not all studies have found a difference associated with small group testing [105]. Deliberate underperformance on baseline testing in an effort to 'sandbag' has received limited attention given the fact that sandbagging has been found to occur in anywhere between 13 and $26 \%$ of athletes [106], although properly trained test administrators are usually able to detect such sandbagging [107]. How frequently an athlete should undergo baseline testing is another question without clear empirical guidance, particularly for children and teens who are still undergoing active cognitive development. A number of individual factors have also been found to affect neuropsychological test performance, which could influence whether an athlete is considered recovered from a concussion or not. For example, youth with attention-deficit/hyperactivity disorder [108,109] or learning disorders [108] perform more poorly on some baseline tests. Moreover, a large number of variables can influence symptom reporting on questionnaires that are often given during baseline testing, such as attention-deficit/hyperactivity disorder, learning disabilities, mental health difficulties, somatization and insufficient sleep [39,110-112].

These complexities render interpretation of neurocognitive tests more challenging than some might believe based on the seemingly straightforward 'red light, green light' approach produced by a number of computerized neurocognitive batteries. As such, neuropsychologists are now recognized as the best trained professionals to interpret neurocognitive test results, given expertise in psychometrics and knowledge of both brain injury and nonbrain injury effects on cognitive test performance [92]. In the end, neurocognitive testing can contribute useful clinical information after concussion. It can be particularly helpful when integrated into a more comprehensive multidimensional postconcussion assessment. Of note, because the etiology of persistent symptoms after concussion often involves neurologic and psychosocial factors, neuro-psychological evaluation by a neuropsychologist is recognized as important in disentangling injury and noninjury effects $[92,113]$ and may even be useful as an intervention itself for reducing persistent symptoms [114].

\section{Dual-task gait}

As discussed previously, many concussion evaluations probe single attention-focused abilities, such as quiet stance tasks, gait tasks or computerized neurocognitive tasks. Although these forms of assessment are a valuable component of the multifaceted concussion testing battery $[42,52,92]$, combining both cognitive and motor function paradigms into a single assessment paradigm provides a method to increase task complexity, and potentially to identify deficits after concussion that are not detected with single-task assessments [84]. The ability to divide attention across multiple domains may be indicative of real-life activities. Because attention can be impaired after concussion [63,64], completing two competing tasks simultaneously may be more difficult for those who recently sustained a concussion compared with those who did not. Therefore, dual-task paradigms may be uniquely equipped to assess functional recovery after a concussion. Specifically, gait deficits during dual-task conditions appear to be more apparent compared with single-task conditions $[3,82,84,115]$.

The test characteristics of dual-task gait paradigms have not been well-established to this point, particularly compared with more researched tests of neurocognitive function. Instead, much of the literature has focused on the comparison of acute postconcussion performance with matched controls within adolescent and young adult athletic populations. Questions remain about whether dual-task gait paradigms have adequate reliability, validity and sensitivity to be useful in clinical practice. Two recent studies have reported medium-to-high test-retest reliability for dual-task gait paradigms among healthy young adults [116] and healthy young adults and adolescents [79]. Specifically, when tested approximately 6 months apart, uninjured collegiate athletes had acceptable dual-task gait intraclass coefficient values ranging from 0.73 to 0.85 [116]. When adolescents were tested on five separate occasions over the period of 2 months, they also had acceptable levels of test consistency on dual-task gait balance control measures (Cronbach's $\alpha$ range $=0.79-0.96$ ). Therefore, dual-task gait appears to be at least a reliable method for repeat administration among uninjured athletes (Table 1).

Several investigations have observed that when gait and cognitive tasks are performed simultaneously, athletes with a concussion display deficits not otherwise detected. Within $48 \mathrm{~h}$ of concussion, collegiate athletes display greater COM sway than matched controls during a dual task consisting of spelling five-letter words in reverse, subtraction by sevens or reciting the months of the year in reverse order while walking [81]. No between-group 
Table 1. Dual-task gait characteristic variables that have been reported to assist with detecting postconcussion deficits.

\begin{tabular}{|c|c|c|}
\hline Gait characteristic & Postconcussion deficits & Reliability \\
\hline Average walking speed & $\begin{array}{l}\text { Slower among those with concussion than controls [122] } \\
\text { Higher dual-task costs compared with controls }[3,82]\end{array}$ & $\begin{array}{l}\text { Cronbach's } \alpha=0.94-0.96[79] \\
I C C=0.77[116]\end{array}$ \\
\hline Stride length & $\begin{array}{l}\text { Shorter after recent concussion in those with history of multiple } \\
\text { concussions than controls [123] }\end{array}$ & $\begin{array}{l}\text { Cronbach's } \alpha=0.90-0.91[79] \\
\mathrm{ICC}=0.73[116]\end{array}$ \\
\hline Double-leg stance support time & $\begin{array}{l}\text { Greater among those with a history of concussion compared with those } \\
\text { without a history of concussion [124] }\end{array}$ & Not available \\
\hline COM peak medial-lateral velocity & $\begin{array}{l}\text { Faster side-to-side movement during dual-task gait than single-task gait } \\
\text { after concussion }[3,82]\end{array}$ & Cronbach's $\alpha=0.85-0.89$ [79] \\
\hline
\end{tabular}

differences, however, were identified during the walking only condition. Similarly, while other measures of dynamic balance control such as the peak velocity of the COM (a measurement taking into account both stride length and stride time) revealed initial postinjury deficits, no single-task differences were found between concussed and control groups across a 1 month postinjury timeline [117].

From the time of injury and throughout the ensuing recovery, athletes have also consistently shown greater deficits during dual-task walking relative to single-task walking after a concussion [3,118]. Some adolescent athletes walk with greater dual-task medial-lateral COM sway throughout a 2-month period after concussion relative to their own single-task performance and to the dual-task gait characteristics of matched controls [3]. Furthermore, the specific type of cognitive task that an individual performs during gait influences the amount of dynamic instability after a concussion, where more complex cognitive tasks are associated with greater dynamic instability [84]. Although Fino observed higher dual-task costs (i.e., the relative change from single-task to dual-task gait measures) among athletes after a concussion for gait speed, stride time variability or local dynamic stability [82], single-task gait speed differences were also detected between concussion and control groups. The degree to which these differences were observed varied by task, however, the addition of an arithmetic task during gait generated a greater destabilizing effect on those with a concussion. This was interpreted to suggest that while single-task gait may provide some beneficial information about recovery from concussion, dual tasks disrupt gait patterns and stability of those with concussion to a greater degree than single-task assessments [82].

Collectively, these studies demonstrate that across different age groups, testing timelines after concussion, and measurement devices, dual-task deficits are more apparent and continue to persist longer postconcussion than single-task gait deficits. This has implications for clinical practice, because many commonly used testing methods rely primarily on single-task paradigms. Using single-task paradigms alone may result in clinicians not being able to identify subtle, yet potentially meaningful neuromuscular control deficits among athletes prior to resumption of full athletic participation. Because dual-task testing may be more representative of the demands of sport than single-task tests, their inclusion during postconcussion examinations may help to identify those potentially at risk for another injury that may be missed using standard measures.

\section{Return to play}

One area of recent interest to concussion researchers has been identifying impairments that continue to persist beyond clinical recovery when defined using 'traditional' measures (e.g., symptom burden returned to zero or baseline, normal or baseline neurocognitive test scores and normal or baseline BESS scores). This area of investigation is highly relevant to clinicians involved in the management of sport-related concussion, as accurate identification of when an individual has fully recovered from injury is an essential aspect of determining when it is appropriate for them to return to athletics. Although many studies have continued to follow athletes after concussion until they resume full athletic participation, few have continued to examine the effects beyond this point in time. Electroencephalographic evidence indicates that some individuals continue to exhibit neurophysiological differences a week after concussion, despite performing at a similar level as controls on traditional neurocognitive tests [16]. 
Such a phenomenon may underlie the ability for an athlete to 'pass' the traditional battery of clinical concussion tests yet still be experiencing physiologic dysfunction.

Using motion analysis, Parker et al. observed a 20\% increase of COM movement (i.e., worsening neuromuscular control) among participants between 2 weeks and 1 month after concussion, while all had been cleared to return to play within the first 2 weeks of injury [119]. The authors hypothesized that the combination of incomplete recovery and return to full sports too soon after injury may have led to these changes, and that medial-lateral COM sway during dual-task gait may be a particularly sensitive variable to neuromuscular function. Similarly, elite athletes tested approximately 37 days following a concussion who did not present with postconcussion symptoms and scored similarly as controls on a battery of neuropsychological tests still showed navigational deficits in complex environments during gait [120]. Furthermore, among a sample of children approximately 43 days after a concussion who reported recovery of symptoms, single-task gait stride widths were significantly higher than controls [121]. The authors theorized that trouble integrating sensory information may have resulted in difficulty generating an appropriate motor output during tasks that require adequate neuromuscular function. No dual-task gait deficits were detected in this study, however, which the authors attributed to the use of a cognitive test during gait that was not complex enough to identify between-group differences [121]. Finally, using a prospective design, an altered course of recovery was found on dual-task gait balance control measures before and after athletes were cleared to fully resume pre-injury levels of athletic participation [118]. Although improvements were found immediately prior to resumption of athletic activities among all measurements, a worsening occurred in the ability to maintain dynamic stability during dual-task gait after resuming full participation in athletic activities. In conjunction, no changes were found after athletic activity resumption for single-task gait, symptom severity or computerized attention measurements. Thus, these findings further support the notion that although athletes are able to pass the clinical battery of tests and subsequently return to play, they may still be experiencing functional deficits.

Although dual-task gait paradigms appear to possess utility for concussion management protocols, the literature to date remains limited in many aspects. As mentioned previously, dual-task gait paradigm test characteristics have yet to be firmly established. Furthermore, few studies have investigated athletic populations younger than high school or older than college aged. One study of children who were an average age of 13 years observed dynamic single-task deficits compared with controls, but was conducted in a cross-sectional manner, so the length of time required for this younger population to recover after concussion remains difficult to determine [121]. Among older individuals, a group of elite athletes were tested at a similar postinjury testing time and also, despite no presence of clinical deficits, individuals with a concussion displayed dual-task gait under complex navigational environments [120]. As few studies have investigated how age affects gait balance control recovery after concussion [61], more work is needed to directly understand age group recovery differences during single-task and dual-task gait.

\section{Conclusion}

Gait characteristics and cognitive abilities are affected by concussion. Although assessing each of these domains in isolation is useful in evaluating an athlete with a concussion, the simultaneous execution of both a gait and cognitive task may induce additional complexity that allows for the identification of impairments beyond those identified with traditional concussion tests. Thus, each of these different test forms can contribute meaningful clinical information after a concussion, and should be used within multifaceted postconcussion assessments based on the needs and limitations for each clinical setting.

\section{Executive summary}

- Many objective tests have been developed to assist with clinical decision-making following concussion.

- No single test will provide perfect sensitivity and specificity to identify all concussion-related deficits.

- Dual-task gait tests combine a cognitive and balance test simultaneously, potentially allowing clinicians to detect subtle concussion-related impairments. 
and Neck Injuries in Young Athletes and Wolters Kluwer for working as an author for UpToDate. His research is funded, in part, by philanthropic support from the National Hockey League Alumni Association through the Corey C Griffin Pro-Am Tournament and by a grant from the Football Players Health Study at Harvard University, which is funded by the NFL Players Association. GL Iverson has been reimbursed by the government, professional scientific bodies and commercial organizations for discussing or presenting research relating to mild TBI and sport-related concussion at meetings, scientific conferences and symposiums. He has a clinical and consulting practice in forensic neuropsychology involving individuals who have sustained mild TBIs (including professional athletes). He has received past research funding from several test publishing companies, including ImPACT Applications, Inc., CNS Vital Signs and Psychological Assessment Resources (PAR, Inc.). He acknowledges unrestricted philanthropic support from the Mooney-Reed Charitable Foundation and ImPACT Applications, Inc. MW Kirkwood receives royalties from Guilford Press for the sale of his books Mild Traumatic Brain Injury in Children and Adolescents and Validity Testing in Child and Adolescent Assessment. The authors have no other relevant affiliations or financial involvement with any organization or entity with a financial interest in or financial conflict with the subject matter or materials discussed in the manuscript apart from those disclosed.

No writing assistance was utilized in the production of this manuscript.

Open access

This work is licensed under the Creative Commons Attribution 4.0 License. To view a copy of this license, visit http://creativecomm ons.org/licenses/by/4.0/

\section{References}

1. Broglio SP, Puetz TW. The effect of sport concussion on neurocognitive function, self-report symptoms and postural control: a meta-analysis. Sports Med. 38(1), 53-67 (2008).

2. Lee H, Sullivan SJ, Schneiders AG. The use of the dual-task paradigm in detecting gait performance deficits following a sports-related concussion: a systematic review and meta-analysis. J. Sci. Med. Sport. 16(1), 2-7 (2013).

3. Howell DR, Osternig LR, Chou L-S. Dual-task effect on gait balance control in adolescents with concussion. Arch. Phys. Med. Rehabil. 94(8), 1513-1520 (2013).

4. Powers KC, Kalmar JM, Cinelli ME. Recovery of static stability following a concussion. Gait Posture 39(1), 611-614 (2014).

5. McCrea M, Guskiewicz KM, Marshall SW et al. Acute effects and recovery time following concussion in collegiate football players: the NCAA concussion study. JAMA 290(19), 2556-2563 (2003).

6. Mucha A, Collins MW, Elbin RJ et al. A brief Vestibular/Ocular Motor Screening (VOMS) assessment to evaluate concussions: preliminary findings. Am. J. Sports Med. 42(10), 2479-2486 (2014).

7. Kontos AP, Sufrinko A, Elbin RJ, Puskar A, Collins MW. Reliability and associated risk factors for performance on the Vestibular/Ocular Motor Screening (VOMS) tool in healthy collegiate athletes. Am. J. Sports Med. 44(6), 1400-1406 (2016).

8. Sufrinko AM, Marchetti GF, Cohen PE, Elbin RJ, Re V, Kontos AP. Using acute performance on a comprehensive neurocognitive, vestibular, and ocular motor assessment battery to predict recovery duration after sport-related concussions. Am. J. Sports Med. 45(5), 1187-1194 (2017).

9. Zhou G, Brodsky JR. Objective vestibular testing of children with dizziness and balance complaints following sports-related concussions. Otolaryngol. Head Neck Surg. 152(6), 1133-1139 (2015).

10. Kontos AP, Elbin RJ, Schatz P et al. A revised factor structure for the post-concussion symptom scale: baseline and postconcussion factors. Am. J. Sports Med. 40(10), 2375-2384 (2012).

11. Lau BC, Collins MW, Lovell MR. Sensitivity and specificity of subacute computerized neurocognitive testing and symptom evaluation in predicting outcomes after sports-related concussion. Am. J. Sports Med. 39(6), 1209-1216 (2011).

12. Howell DR, O'Brien MJ, Beasley MA, Mannix RC, Meehan WP. Initial somatic symptoms are associated with prolonged symptom duration following concussion in adolescents. Acta Paediatr. 105(9), e426-e432 (2016).

13. Toledo E, Lebel A, Becerra L et al. The young brain and concussion: imaging as a biomarker for diagnosis and prognosis. Neurosci. Biobehav. Rev. 36(6), 1510-1531 (2012).

14. Koerte IK, Hufschmidt J, Muehlmann M, Lin AP, Shenton ME. Advanced neuroimaging of mild traumatic brain injury. In: Translational Research in Traumatic Brain Injury. Laskowitz D, Grant G (Eds). CRC Press/Taylor and Francis Group, FL, USA (2016).

15. Mayinger MC, Merchant-Borna K, Hufschmidt J et al. White matter alterations in college football players: a longitudinal diffusion tensor imaging study. Brain Imaging Behav. doi:10.1007/s11682-017-9672-4 (2017) (Epub ahead of print).

16. Teel EF, Ray WJ, Geronimo AM, Slobounov SM. Residual alterations of brain electrical activity in clinically asymptomatic concussed individuals: an EEG study. Clin. Neurophysiol. 125(4), 703-707 (2014).

17. Slobounov $S$, Sebastianelli W, Hallett M. Residual brain dysfunction observed one year post-mild traumatic brain injury: combined EEG and balance study. Clin. Neurophysiol. 123(9), 1755-1761 (2012). 
18. Slobounov S, Cao C, Sebastianelli W. Differential effect of first versus second concussive episodes on wavelet information quality of EEG. Clin. Neurophysiol. 120(5), 862-867 (2009).

19. Broglio SP, Ferrara MS, Macciocchi SN, Baumgartner TA, Elliott R. Test-retest reliability of computerized concussion assessment programs. J. Athl. Train. 42(4), 509-514 (2007).

20. MacDonald J, Duerson D. Reliability of a computerized neurocognitive test in baseline concussion testing of high school athletes. Clin. J. Sport Med. 25(4), 367-372 (2015).

21. Meehan WP, d'Hemecourt P, Collins CL, Taylor AM, Comstock RD. Computerized neurocognitive testing for the management of sport-related concussions. Pediatrics 129(1), 38-44 (2012).

22. Finnoff JT, Peterson VJ, Hollman JH, Smith J. Intrarater and interrater reliability of the Balance Error Scoring System (BESS). PM $R$ 1(1), 50-54 (2009).

23. Bell DR, Guskiewicz KM, Clark MA, Padua DA. Systematic review of the balance error scoring system. Sports Health 3(3), 287-295 (2011).

24. Randolph C, Millis S, Barr WB et al. Concussion symptom inventory: an empirically derived scale for monitoring resolution of symptoms following sport-related concussion. Arch. Clin. Neuropsychol. 24(3), 219-229 (2009).

25. Dillard C, Ditchman N, Nersessova K et al. Post-concussion symptoms in mild traumatic brain injury: findings from a paediatric outpatient clinic. Disabil. Rehabil. 39(6), 544-550 (2016).

26. Lau BC, Kontos AP, Collins MW, Mucha A, Lovell MR. Which on-field signs/symptoms predict protracted recovery from sport-related concussion among high school football players? Am. J. Sports Med. 39(11), 2311-2318 (2011).

27. Baugh CM, Kroshus E, Stamm JM, Daneshvar DH, Pepin MJ, Meehan WP. Clinical practices in collegiate concussion management. Am. J. Sports Med. 44(6), 1391-1399 (2016).

28. Buckley TA, Burdette G, Kelly K. Concussion-management practice patterns of National Collegiate Athletic Association Division II and III Athletic Trainers: how the other half lives. J. Athl. Train. 50(8), 879-888 (2015).

29. Makdissi M, Darby D, Maruff P, Ugoni A, Brukner P, McCrory PR. Natural history of concussion in sport: markers of severity and implications for management. Am. J. Sports Med. 38(3), 464-471 (2010).

30. Ellis MJ, Cordingley DM, Vis S, Reimer KM, Leiter J, Russell K. Clinical predictors of vestibulo-ocular dysfunction in pediatric sports-related concussion. J. Neurosurg. Pediatr. 19(1), 38-45 (2017).

31. McCrea M, Guskiewicz K, Randolph C et al. Incidence, clinical course, and predictors of prolonged recovery time following sport-related concussion in high school and college athletes. J. Int. Neuropsychol. Soc. 19(1), 22-33 (2013).

32. Meehan WP 3rd, d'Hemecourt P, Collins CL, Comstock RD. Assessment and management of sport-related concussions in United States high schools. Am. J. Sports Med. 39(11), 2304-2310 (2011).

33. Gaetz MB, Iverson GL. Sex differences in self-reported symptoms after aerobic exercise in non-injured athletes: implications for concussion management programmes. Br. J. Sports Med. 43(7), 508-513 (2009).

34. Balasundaram AP, Sullivan JS, Schneiders AG, Athens J. Symptom response following acute bouts of exercise in concussed and non-concussed individuals - a systematic narrative review. Phys. Ther. Sport 14(4), 253-258 (2013).

35. Burk JM, Munkasy BA, Joyner AB, Buckley TA. Balance error scoring system performance changes after a competitive athletic season. Clin. J. Sport Med. 23(4), 312-317 (2013).

36. Rahn C, Munkasy BA, Joyner AB, Buckley TA. Sideline performance of the balance error scoring system during a live sporting event. Clin. J. Sport Med. 25(3), 248-253 (2014).

37. Wilkins JC, Valovich McLeod TC, Perrin DH, Gansneder BM. Performance on the balance error scoring system decreases after fatigue. J. Athl. Train. 39(2), 156-161 (2004).

38. Azad AM, Al Juma S, Bhatti JA, Delaney JS. Modified Balance Error Scoring System (M-BESS) test scores in athletes wearing protective equipment and cleats. BMJ Open Sport Exerc. Med. 2(1), e000117 (2016).

39. McClure DJ, Zuckerman SL, Kutscher SJ, Gregory AJ, Solomon GS. Baseline neurocognitive testing in sports-related concussions: the importance of a prior night's sleep. Am. J. Sports Med. 42(2), 472-478 (2014).

40. Littleton AC, Schmidt JD, Register-Mihalik JK et al. Effects of attention deficit hyperactivity disorder and stimulant medication on concussion symptom reporting and computerized neurocognitive test performance. Arch. Clin. Neuropsychol. 30(7), 683-693 (2015).

41. Gardner RM, Yengo-Kahn A, Bonfield CM, Solomon GS. Comparison of baseline and post-concussion ImPACT test scores in young athletes with stimulant-treated and untreated ADHD. Phys. Sportsmed. 45(1), 1-10 (2016).

42. Broglio SP, Cantu RC, Gioia GA et al. National Athletic Trainers' Association position statement: management of sport concussion. J. Athl. Train. 49(2), 245-265 (2014).

43. Hänninen T, Tuominen M, Parkkari J et al. Sport concussion assessment tool - 3rd edition - normative reference values for professional ice hockey players. J. Sci. Med. Sport 19(8), 636-641 (2015).

44. Howell DR, Meehan WP. Normative values for a video-force plate assessment of postural control in athletic children. J. Pediatr. Orthop. Part B 25(4), 310-314 (2016). 
45. Iverson GL, Koehle MS. Normative data for the modified balance error scoring system in adults. Brain Inj. 27(5), 596-599 (2013).

46. Iverson GL, Lovell MR, Collins MW. Immediate Post-Concussion Assessment and Cognitive Testing (ImPACT) normative data. Pittsburgh, PA: University of Pittsburgh. J. Athl. Train. 44(6), 639-644 (2009).

47. Oldham JR, DiFabio MS, Kaminski TW, DeWolf RM, Buckley TA. Normative tandem gait in collegiate student-athletes implications for clinical concussion assessment. Sports Health Multidiscip. Approach 9(4), 305-311 (2016)

48. Scheiman M, Gallaway M, Frantz KA et al. Nearpoint of convergence: test procedure, target selection, and normative data. Optom. Vis. Sci. 80(3), 214-225 (2003).

49. Vartiainen MV, Holm A, Peltonen K, Luoto TM, Iverson GL, Hokkanen L. King-Devick test normative reference values for professional male ice hockey players. Scand. J. Med. Sci. Sports. 25(3), e327-e330 (2015).

50. Zimmer A, Marcinak J, Hibyan S, Webbe F. Normative values of major SCAT2 and SCAT3 components for a college athlete population. Appl. Neuropsychol. Adult 22(2), 132-140 (2015).

51. Schmidt JD, Register-Mihalik JK, Mihalik JP, Kerr ZY, Guskiewicz KM. Identifying impairments after concussion: normative data versus individualized baselines. Med. Sci. Sports Exerc. 44(9), 1621-1628 (2012).

52. McCrory P, Meeuwisse W, Dvorak J et al. Consensus statement on concussion in sport - the 5 th international conference on concussion in sport held in Berlin, October 2016. Br. J. Sports Med. 51(11), 838-847 (2017).

53. Winter D. Human balance and posture control during standing and walking. Gait Posture 3(4), 193-214 (1995).

54. Sutherland DH, Olshen R, Cooper L, Woo SL. The development of mature gait. J. Bone Joint Surg. Am. 62(3), 336-353 (1980).

55. Yogev-Seligmann G, Hausdorff JM, Giladi N. The role of executive function and attention in gait. Mov. Disord. 23(3), 329-342 (2008).

56. Kelly KC, Jordan EM, Joyner AB, Burdette GT, Buckley TA. National Collegiate Athletic Association Division I athletic trainers' concussion-management practice patterns. J. Athl. Train. 49(5), 665-673 (2014).

57. Register-Mihalik JK, Littleton AC, Guskiewicz KM. Are divided attention tasks useful in the assessment and management of sport-related concussion? Neuropsychol. Rev. 23(4), 300-313 (2013).

58. Catena RD, van Donkelaar P, Chou L-S. Altered balance control following concussion is better detected with an attention test during gait. Gait Posture 25(3), 406-411 (2007).

59. Chiu S-L, Osternig L, Chou L-S. Concussion induces gait inter-joint coordination variability under conditions of divided attention and obstacle crossing. Gait Posture 38(4), 717-722 (2013).

60. Pai Y-C, Patton J. Center of mass velocity-position predictions for balance control. J. Biomech. 30(4), 347-354 (1997).

61. Howell DR, Osternig LR, Chou L-S. Adolescents demonstrate greater gait balance control deficits after concussion than young adults. Am. J. Sports Med. 43(3), 625-632 (2015).

62. Van Kampen DA, Lovell MR, Pardini JE, Collins MW, Fu FH. The "value added" of neurocognitive testing after sports-related concussion. Am. J. Sports Med. 34(10), 1630-1635 (2006).

63. Howell DR, Osternig L, van Donkelaar P, Mayr U, Chou L-S. Effects of concussion on attention and executive function in adolescents. Med. Sci. Sports Exerc. 45(6), 1030-1037 (2013).

64. Halterman CI, Langan J, Drew A et al. Tracking the recovery of visuospatial attention deficits in mild traumatic brain injury. Brain 129(3), 747-753 (2006).

65. Guskiewicz KM, Register-Mihalik J, McCrory P et al. Evidence-based approach to revising the SCAT2: introducing the SCAT3. Br. J. Sports Med. 47(5), 289-293 (2013).

66. Grindel SH, Lovell MR, Collins MW. The assessment of sport-related concussion: the evidence behind neuropsychological testing and management. Clin. J. Sport Med. 11(3), 134-143 (2001).

67. Barth JT, Alves WM, Ryan TV et al. Mild Head Injury in Sports: Neuropsychological Sequelae and Recovery of Function. Levin HS, Eisenberg HM, Benton AL (Eds). Oxford University Press, Oxford, UK, 257-275 (1989).

68. Alves WM, Rimel RW, Nelson WE. University of Virginia prospective study of football-induced minor head injury: status report. Clin. Sports Med. 6(1), 211-218 (1987).

69. Camicioli R, Howieson D, Lehman S, Kaye J. Talking while walking: the effect of a dual task in aging and Alzheimer's disease. Neurology 48(4), 955-958 (1997).

70. Springer S, Giladi N, Peretz C, Yogev G, Simon ES, Hausdorff JM. Dual-tasking effects on gait variability: the role of aging, falls, and executive function. Mov. Disord. 21(7), 950-957 (2006).

71. Beauchet O, Berrut G. Gait and dual-task: definition, interest, and perspectives in the elderly. Psychol. Neuropsychiatr. Vieil. 4(3), 215-225 (2006).

72. Tapper A, Gonzalez D, Roy E, Niechwiej-Szwedo E. Executive function deficits in team sport athletes with a history of concussion revealed by a visual-auditory dual task paradigm. J. Sports Sci. 35(3), 231-240 (2017).

73. Resch JE, May B, Tomporowski PD, Ferrara MS. Balance performance with a cognitive task: a continuation of the dual-task testing paradigm. J. Athl. Train. 46(2), 170-175 (2011). 
74. Ross L, Register-Mihalik J, Mihalik J et al. Effects of a single-task versus a dual-task paradigm on cognition and balance in healthy subjects. J. Sport Rehabil. 20(3), 296 (2011).

75. Moher D, Liberati A, Tetzlaff J, Altman DG, PRISMA Group. Preferred reporting items for systematic reviews and meta-analyses: the PRISMA statement. Ann. Intern. Med. 151(4), 264-269, W64 (2009).

76. Taga G. A model of the neuro-musculo-skeletal system for human locomotion. I. Emergence of basic gait. Biol. Cybern. 73(2), 97-111 (1995).

77. Dietz V, Schmidtbleicher D, Noth J. Neuronal mechanisms of human locomotion. J. Neurophysiol. 42(5), 1212-1222 (1979).

78. Borghese NA, Bianchi L, Lacquaniti F. Kinematic determinants of human locomotion. J. Physiol. 494(Pt 3), 863-879 (1996).

79. Howell DR, Osternig LR, Chou L-S. Consistency and cost of dual-task gait balance measure in healthy adolescents and young adults. Gait Posture 49, 176-180 (2016).

80. Catena RD, Donkelaar P, Chou L-S. Cognitive task effects on gait stability following concussion. Exp. Brain Res. 176(1), 23-31 (2006).

81. Parker TM, Osternig LR, Lee H-J, Donkelaar Pv, Chou L-S. The effect of divided attention on gait stability following concussion. Clin. Biomech. 20(4), 389-395 (2005).

82. Fino PC. A preliminary study of longitudinal differences in local dynamic stability between recently concussed and healthy athletes during single and dual-task gait. J. Biomech. 49(9), 1983-1988 (2016).

83. Buckley TA, Vallabhajosula S, Oldham JR et al. Evidence of a conservative gait strategy in athletes with a history of concussions. J. Sport Health Sci. 5(4), 417-423 (2016).

84. Howell DR, Osternig LR, Koester MC, Chou L-S. The effect of cognitive task complexity on gait stability in adolescents following concussion. Exp. Brain Res. 232(6), 1773-1782 (2014).

85. Lugade V, Lin V, Chou L-S. Center of mass and base of support interaction during gait. Gait Posture 33(3), 406-411 (2011).

86. Chou L-S, Kaufman KR, Hahn ME, Brey RH. Medio-lateral motion of the center of mass during obstacle crossing distinguishes elderly individuals with imbalance. Gait Posture 18(3), 125-133 (2003).

87. Chou LS, Kaufman KR, Brey RH, Draganich LF. Motion of the whole body's center of mass when stepping over obstacles of different heights. Gait Posture 13(1), 17-26 (2001).

88. Karr JE, Areshenkoff CN, Garcia-Barrera MA. The neuropsychological outcomes of concussion: a systematic review of meta-analyses on the cognitive sequelae of mild traumatic brain injury. Neuropsychology 28(3), 321-336 (2014).

89. Dougan BK, Horswill MS, Geffen GM. Do injury characteristics predict the severity of acute neuropsychological deficits following sports-related concussion? A meta-analysis. J. Int. Neuropsychol. Soc. 20(1), 81-87 (2014).

90. Iverson GL. Mild traumatic brain injury meta-analyses can obscure individual differences. Brain Inj. 24(10), 1246-1255 (2010).

91. McCrea M, Barr WB, Guskiewicz K et al. Standard regression-based methods for measuring recovery after sport-related concussion. $J$. Int. Neuropsychol. Soc. 11(1), 58-69 (2005).

92. McCrory P, Meeuwisse WH, Aubry M et al. Consensus statement on concussion in sport: the 4th International Conference on Concussion in Sport, Zurich, November 2012. J. Athl. Train. 48(4), 554-575 (2013).

93. Harmon KG, Drezner JA, Gammons M et al. American Medical Society for Sports Medicine position statement: concussion in sport. Br. J. Sports Med. 47(1), 15-26 (2013).

94. McCrory P, Johnston K, Meeuwisse W et al. Summary and agreement statement of the 2nd international conference on concussion in Sport, Prague 2004. Br. J. Sports Med. 39(4), 196-204 (2005).

95. Giza CC, Kutcher JS, Ashwal S et al. Summary of evidence-based guideline update: evaluation and management of concussion in sports: report of the Guideline Development Subcommittee of the American Academy of Neurology. Neurology 80(24), 2250-2257 (2013).

96. Moser RS, Iverson GL, Echemendia RJ et al. Neuropsychological evaluation in the diagnosis and management of sports-related concussion. Arch. Clin. Neuropsychol. 22(8), 909-916 (2007).

97. Iverson G. Predicting slow recovery from sport-related concussion: the new simple-complex distinction. Clin. J. Sport Med. 17(1), 31-37 (2007).

98. Broglio SP, Macciocchi SN, Ferrara MS. Neurocognitive performance of concussed athletes when symptom free. J. Athl. Train. 42(4), 504-508 (2007).

99. Randolph C, McCrea M, Barr WB. Is neuropsychological testing useful in the management of sport-related concussion? J. Athl. Train. 40(3), 139-152 (2005).

100. Resch JE, McCrea MA, Cullum CM. Computerized neurocognitive testing in the management of sport-related concussion: an update. Neuropsychol. Rev. 23(4), 335-349 (2013).

101. Nelson LD, LaRoche AA, Pfaller AY et al. Prospective, head-to-head study of three computerized neurocognitive assessment tools (CNTs): reliability and validity for the assessment of sport-related concussion. J. Int. Neuropsychol. Soc. 22(1), 24-37 (2016).

102. Chin EY, Nelson LD, Barr WB, McCrory P, McCrea MA. Reliability and validity of the Sport Concussion Assessment Tool-3 (SCAT3) in high school and collegiate athletes. Am. J. Sports Med. 44(9), 2276-2285 (2016). 
103. Echemendia RJ, Bruce JM, Bailey CM, Sanders JF, Arnett P, Vargas G. The utility of post-concussion neuropsychological data in identifying cognitive change following sports-related MTBI in the absence of baseline data. Clin. Neuropsychol. 26(7), 1077-1091 (2012).

104. Moser RS, Schatz P, Neidzwski K, Ott SD. Group versus individual administration affects baseline neurocognitive test performance. Am. J. Sports Med. 39(11), 2325-2330 (2011).

105. Vaughan CG, Gerst EH, Sady MD, Newman JB, Gioia GA. The relation between testing environment and baseline performance in child and adolescent concussion assessment. Am. J. Sports Med. 42(7), 1716-1723 (2014).

106. Hill BD, Womble MN, Rohling ML. Logistic regression function for detection of suspicious performance during baseline evaluations using concussion vital signs. Appl. Neuropsychol. Adult. 22(3), 233-240 (2015).

107. Erdal K. Neuropsychological testing for sports-related concussion: how athletes can sandbag their baseline testing without detection. Arch. Clin. Neuropsychol. 27(5), 473-479 (2012).

108. Zuckerman SL, Lee YM, Odom MJ, Solomon GS, Sills AK. Baseline neurocognitive scores in athletes with attention deficit-spectrum disorders and/or learning disability. J. Neurosurg. Pediatr. 12(2), 103-109 (2013).

109. Brooks BL, Iverson GL, Atkins JE, Zafonte R, Berkner PD. Sex differences and self-reported attention problems during baseline concussion testing. Appl. Neuropsychol. Child. 5(2), 119-126 (2016).

110. Nelson LD, Tarima S, LaRoche AA et al. Preinjury somatization symptoms contribute to clinical recovery after sport-related concussion. Neurology 86(20), 1856-1863 (2016).

111. Silverberg ND, Berkner PD, Atkins JE, Zafonte R, Iverson GL. Relationship between short sleep duration and preseason concussion testing. Clin. J. Sport Med. 26(3), 226-231 (2016).

112. Iverson GL, Silverberg ND, Mannix R et al. Factors associated with concussion-like symptom reporting in high school athletes. JAMA Pediatr. 169(12), 1132-1140 (2015).

113. McCrory P, Meeuwisse W, Johnston $\mathrm{K}$ et al. Consensus statement on concussion in sport: the 3rd international conference on concussion in sport held in Zurich, November 2008. J. Athl. Train. 44(4), 434-448 (2009).

114. Kirkwood MW, Peterson RL, Connery AK, Baker DA, Forster J. A pilot study investigating neuropsychological consultation as an intervention for persistent postconcussive symptoms in a pediatric sample. J. Pediatr. 169, 244.e1-249.e1 (2016).

115. Howell DR, Osternig LR, Chou L-S. Single-task and dual-task tandem gait test performance after concussion. J. Sci. Med. Sport. 20(7), 622-626 (2017).

116. Howell DR, Oldham JR, DiFabio M et al. Single-task and dual-task gait among collegiate athletes of different sport classifications: implications for concussion management. J. Appl. Biomech. 33(1), 24-31 (2017).

117. Catena R, van Donkelaar P, Chou L-S. Different gait tasks distinguish immediate versus long-term effects of concussion on balance control. J. Neuroeng. Rehabil. 6(1), 1-7 (2009).

118. Howell DR, Osternig LR, Chou L-S. Return to activity after concussion affects dual-task gait balance control recovery. Med. Sci. Sports Exerc. 47(4), 673-680 (2015).

119. Parker TM, Osternig LR, Van Donkelaar P, Chou L-S. Gait stability following concussion. Med. Sci. Sports Exerc. 38(6), 1032-1040 (2006).

120. Fait P, Swaine B, Cantin J-F, Leblond J, McFadyen BJ. Altered integrated locomotor and cognitive function in elite athletes 30 days postconcussion: a preliminary study. J. Head Trauma Rehabil. 28(4), 293-301 (2013).

121. Sambasivan K, Grilli L, Gagnon I. Balance and mobility in clinically recovered children and adolescents after a mild traumatic brain injury. J. Pediatr. Rehabil. Med. 8(4), 335-344 (2015).

122. Howell DR, Osternig LR, Chou L-S.. Monitoring recovery of gait balance control following concussion using an accelerometer. $J$. Biomech. 48(12), 3364-3368 (2015).

123. Howell DR, Beasley M, Vopat L, Meehan W. The effect of prior concussion history on dual-task gait following a concussion. $J$. Neurotrauma 34(4), 838-844 (2017).

124. Martini DN, Sabin MJ, DePesa SA et al. The chronic effects of concussion on gait. Arch. Phys. Med. Rehabil. 92(4), 585-589 (2011). 